University of Washington Tacoma

UW Tacoma Digital Commons

SIAS Faculty Publications

School of Interdisciplinary Arts and Sciences

$1-2-2018$

\title{
Cutting Through the Discussion on Caesarean Delivery: Birth Practices as Social Practices
}

Natalie Jolly

University of Washington Tacoma, natjolly@uw.edu

Follow this and additional works at: https://digitalcommons.tacoma.uw.edu/ias_pub

\section{Recommended Citation}

Jolly, Natalie, "Cutting Through the Discussion on Caesarean Delivery: Birth Practices as Social Practices" (2018). SIAS Faculty Publications. 828.

https://digitalcommons.tacoma.uw.edu/ias_pub/828

This Article is brought to you for free and open access by the School of Interdisciplinary Arts and Sciences at UW Tacoma Digital Commons. It has been accepted for inclusion in SIAS Faculty Publications by an authorized administrator of UW Tacoma Digital Commons. 
$\underline{\text { Natalie Jolly }}$

$\underline{\text { Assistant Professor, School of Interdisciplinary Arts \& Sciences }}$

University of Washington Tacoma

natjolly@uw.edu 


\title{
Cutting through the discussion on caesarean delivery:
}

\section{Birth practices as social practices}

\begin{abstract}
Women are finding appeal in (or, at minimum, a lower level of resistance to) caesarean delivery despite the health risks that it poses, and I investigate how this decision figures into a broader pattern of women's gender socialization within a culture that is deeply anxious about women's bodies. I review scholarship on caesarean delivery, and use social practice theory to map possible contact points between theories of embodiment, a sociology of gender, and the specific practice of caesarean section. I consider caesarean delivery as a component of a social practice, and adopt a practice framework to analyze women's motivation for selecting (or consenting to) caesarean delivery. I detail the materiality of the hospital, the medicalization of women's bodies, and women's antagonistic body relationship to reveal some of the less immediately apparent reasons why caesarean delivery has been normalized and rendered invisible as part of the pattern of modern childbirth. Interventions to address the further escalation of caesarean delivery might consider how this decision aligns with other social practices. I conclude that activism addressing the social conditions that make caesarean delivery so attractive may radiate out to other aspects of women's lives where the practices of normative femininity have proven equally restrictive.
\end{abstract}

\section{KEY WORDS}

Caesarean delivery, Social practice theory, gender socialization, medicalization of women's bodies, modern childbirth 


\section{Introduction}

It has been over a decade since Reiger and Dempsey identified "the paradox that a decline in cultural and individual confidence in women's birthing capacity" exists "in spite of western women's increased social power and achievement and improved health and living conditions." (2006, p. 365). Despite their prescient observations about childbirth, and their plea for health researchers to consider questions of reproduction through analyses of women's lived bodies, little has been done to build upon their call that childbirth be seen as "an active embodied practice" (p. 364). In this paper, I take up and extend their theoretical framework and their interdisciplinary enthusiasm to bring together disparate works from feminist and sociological analysis to address one of today's most pressing childbirth concerns: caesarean section. To accomplish this, I consider caesarean delivery through the lens of social practice theory (Reckwitz, 2002; Shove, Pantzar, \& Watson, 2012) to understand why surgical delivery may be gaining popularity and to suggest how medical professionals might address the social and material conditions that have led to surgical delivery having increased appeal.

I begin by reviewing how feminist health scholarship has investigated the norms that govern women's bodies as context for a more specific discussion of caesarean delivery. I then review debates around caesarean delivery and demonstrate that health researchers have commonly found the decision to deliver via caesarean to be either a single decision made by an individual or to be merely the result of broader social forces, over which individuals have little control. I attempt to find a middle ground between these two, and employ practice theory to consider what it would mean to analyze caesarean delivery as a social practice. In the spirit of Reiger and Dempsey's approach to "draw on seemingly disparate work" (p. 364), I review existing scholarship on gender socialization and the medicalization of women's bodies to consider the practice of caesarean delivery in American and Australian contexts. I then marshal existing research to suggest that women's relationship to their bodies is largely negative, and introduce the concepts of women's adversarial body relationship and antagonistic female embodiment as theoretically useful contributions to this area of scholarship. Building on this, I posit that women's adversarial relationship to her body might help to illuminate how a decision to deliver via caesarean may align with other social practices associated with conventional femininity. I 
draw primarily on literature from the United States and Australia to add a new sociological dimension to the ongoing debate around caesarean delivery and what has motivated its rise.

\section{Investigating women's bodies}

Feminist health scholarship has rigorously investigated the cultural meanings and norms that govern women's bodies. From young bodies (Brumberg, 1997) to old (Lock, 1993), social theory on the female body is located at the precise Venn of sex, gender, science, technology, culture and normativity (Fausto-Sterling, 2000; Grosz, 1994; E. Martin, 2001). Much of this work has considered processes of menstruation (Bobel, 2010; Freidenfelds, 2009) and menopause (Lock, 1993; Niland \& Lyons, 2011), and this growing literature has refigured conventional assumptions about the self-evident nature of these processes, and demonstrated the "multiple effects of bodies, experiences, and interactions in particular social, political, and historical contexts" (Almeling, 2015, p. 437). Childbirth has been central to analyses of women's bodies (Brubaker, 2007; Lupton \& Schmied, 2013; Malacrida \& Boulton, 2012; K. Martin, 2003), which is not surprising, given that $82 \%$ of American women (Livingston \& Cohn, 2010) and $84 \%$ of Australian women (Statistics, 2006) give birth at least once during their lifetime. At the forefront of these discussions is the issue of increased medicalization during pregnancy and birth, which has been condensed into a set of more vexed debates around caesarean delivery.

Academic treatment of the $C$-section epidemic in America (Morris, 2013) ranges from theoretical (Beckett, 2005) to structural (Morris, 2013) to ethical (Bergeron, 2007) to medical (Doherty \& Eichenwald, 2004; Ecker, 2013) to personal (Michaluk, 2012). Each provides a new vantage point from which to illuminate the complexity inherent in this public health issue and suggests that the rising rate of caesarean delivery is more than women simply becoming Too Posh to Push (Song, 2004). I add to this literature, and offer a response that "looks to theories of social practice for new ways of understanding health and social phenomena" (Maller, 2015, p. 63). I consider caesarean delivery as a form of social practice, and I adopt Shove, Pantzar and Watson's (2012) social practice framework (based on the theoretical work done by Reckwitz (2002) and Giddens (1979)) to offer a situated and grounded analysis of women's motivation for selecting (or consenting to) caesarean delivery. I use the concepts materials, competences, and 
meanings as an analytic structure to allow for an exploration of how the practice of caesarean may align with other social practices associated with normative gender.

\section{The rising rate of caesarean delivery}

The 2015 "Statement on Caesarean Section Rates" by the World Health Organization (WHO) called attention to the rising rate of caesarean in the developed world. Many Western nations share the high rate of surgical delivery now being observed in the United States (32.2\%) (CDC, 2015) and Australia (33\%) (Welfare, 2015) which falls outside the 10-15\% rate beyond which "there is no evidence that mortality rates improve" (WHO, 2015). This is the second time that the WHO has brought attention to caesarean delivery, though their 1985 missive was more explicit in claiming "no justification for any region to have CS rates higher than $10-15 \%$ " (WHO, 1985). Caesarean delivery is now the most common surgical procedure (Dietz \& Campbell, 2016) and for low-risk women, it has been linked with a neonatal mortality rate nearly 3 times that of vaginal delivery (Macdonald, 2006). Caesarean delivery has been shown to pose higher health risks for mothers and infants (Sevelsted, 2015), cost considerably more than vaginal deliveries (Chen, Liu, Chen, \& Lin, 2014), and necessitate additional postpartum medical care (Declercq et al., 2007). Given this, why are women increasingly delivering via caesarean section?

Some have contended that it is mothers themselves who are driving up the rate of caesarean by electing a surgical delivery without medical indication. Termed maternal request caesarean delivery (MRCD), these are also called 'elective caesarean', referring to "caesarean delivery performed without maternal or fetal indication; i.e., with no expectation of improving the physical health of the mother or neonate" (Ecker, 2013, p. 1931). The elective designation of these deliveries can be misleading, as it can either refer to a medically and obstetrically indicated procedure that is chosen before labor begins or to a procedure for which there is no clear medical or obstetric indication (Miesnik \& Reale, 2007). Much of the concern about MRCD stems from the rising rate of those procedures without clear medical indication, and questions abound regarding women's motivations for an elective surgery that poses serious health risks, incurs greater cost, and results in a longer period of recovery. A woman may be inspired to elect a 
caesarean delivery for a greater level of convenience and more control over the timing of her baby's birth, she may perceive it to offer a higher level of safety for her child, and, similarly, she may believe that it will reduce the risk of incontinence and loss of pelvic floor function after delivery. Because aggregate childbirth data does not clearly designate the motivations for and the context within which a MRCD decision is made, a clear assessment of its frequency is difficult to gauge. Disagreement exists, with estimates ranging from 3\% (Ecker, 2013) to over 7\% (Miesnik \& Reale, 2007) of all deliveries constituting MRCD. And while health researchers and medical practitioners may not agree on the current percentage of births that are MRCD, they have agreed that the rate is climbing; Meikle et al. demonstrated that the number rose $43.6 \%$ between 1994 and 2001 (2007).

Others have argued that MRCD continue to make up a relatively small percentage of total caesarean deliveries, and as such MRCD is not primarily responsible for the ongoing rise in caesarean delivery. Researchers have instead cited demographic and bureaucratic features that have created an environment where caesarean delivery enjoys such prominence. Medical professionals have suggested surgical delivery is increasingly medically necessary because women are having fewer children, are having those children later in life, and are delivering during a time of unprecedented obesity that has brought with it a higher rate of gestational diabetes (Dietz \& Campbell, 2016). More common now, too, is a higher likelihood of multiples (twins, triplets, etc.) and preterm delivery, both of which occur with greater frequency in pregnancies that utilize assisted reproductive technology (Basso \& Baird, 2003). Medicolegal motivations are also seen as justifying the adoption of caesarean delivery as a defensive medical practice, making doctors more willing to suggest it even when not medically necessitated (Murthy, Grobman, Lee, \& Holl, 2007; Zwecker, Azoulay, \& Abenhaim, 2011). Some tie the rising rate of caesarean more explicitly to the demographics of birthing women today and the litigious socio-medical environment in which we find ourselves. Doing so moves culpability solely away from MRCD and situates responsibility for our rising caesarean rate more squarely within a changing social context.

I offer that health scholars may find the distinction between "medically unnecessary" MRCD and "medically necessary" caesareans to be a false one; one that implies that a caesarean decision is either a single decision made by an individual or the result of broader forces, over which 
individuals have little control. Certainly few would disagree that the increasing rate of caesarean delivery constitutes a more general public health concern, and many have explicitly deemed it so (Bergeron, 2007; Klein, 2012; Morris, 2013; Plante, 2006). I echo Reiger and Dempsey in suggesting that we need "a better way to conceptualize the interaction of physiological processes and cultural context" (p. 366) in women's birth decisions. I employ practice theory in the sociological tradition to further advance this.

\section{Social practice theory}

In arguing that social practices constitute the "basic domain of study of the social sciences", Anthony Giddens mapped out an interpretive sociology that relied on social practices as the principal unit of analysis. Tied to Pierre Bourdieu's work on habitus (Bourdieu, 1984) and Michel Foucault's work on discipline (Foucault, 1977), practice theory "seeks to explain the relationship(s) that obtain between human action, on the one hand, and some global entity which we call 'the system' on the other" (Ortner, 1984, p. 148). Others (Reckwitz, 2002; Schatzki, 1996) have similarly found practice theory to be useful in analyzing how individuals both produce and are produced by society. Indeed, we are all carriers of social practice (Reckwitz) and so it follows that social practices should be considered as dynamic entities in their own right. To elucidate what - specifically - constitutes a practice, Reckwitz explains:

A practice is a routinized type of behavior which consists of several elements, interconnected to one another: forms of bodily activities, forms of mental activities, 'things' and their use, a background knowledge in the form of understanding, know-how, states of emotion and motivational knowledge. A practice [...] forms so to speak a 'block' whose existence necessarily depends on the existence and specific interconnectedness of these elements, and which cannot be reduced to any one of these single elements. Likewise, a practice represents a pattern which can be filled out by a multitude of single and often unique actions reproducing the practice. The single individual - as a bodily and mental agent - then acts as the 'carrier' of a practice - and, in fact, of many different practices which need not be coordinated with one another. [...] A 
practice is thus a routinized way in which bodies are moved, objects are handled, subjects are treated, things are described and the world is understood. (pp. 249-250)

Reckwitz's charge to social scientists is to address social problems by beginning with the practice itself as the unit of analysis. I build on the work of others (Creighton \& Oliffe, 2010) who have used practice theory to consider the gendered nature of health choices without reducing the decisions people make to individual behavior nor ascribing them to wider determinants and structural conditions. Considering caesarean as a constitutive element of a social practice allows us to focus specifically on the body:

At the core of practice theory lies a different way of seeing the body. Practices are routinized bodily activities; as interconnected complexes of behavioral acts they are movements of the body. A social practice is the product of training the body in a certain way, when we learn a practice, we learn to be bodies in a certain way (and this means more than to 'use our bodies'). A practice can be understood as the regular, skillful 'performance' of (human) bodies (Reckwitz, 2002, p. 251).

Below I consider caesarean deliveries (MRCD and otherwise) as a practice and discuss how the specific decision to deliver via caesarean may align with other social practices. While not denying the role played by obstetrical practice, hospital policy, and medical insurance, the argument below emphasizes non-medical elements. It builds on existing research which has found that gender norms shape women's experiences of birth and the choices women make during delivery (Brubaker, 2007; Malacrida \& Boulton, 2012; K. Martin, 2003). Further, it shifts the focus from caesarean as an isolated health decision and instead understands caesarean delivery as a form of a practice in its own right.

\section{Caesarean delivery as social practice}

In this section, I draw on Shove, Pantzar and Watson's "idea that practices are defined by interdependent relations between materials, competences and meanings" (Shove et al., 2012, p. 24). I use this schematic to consider how caesarean delivery might be understood within a practice framework to reveal some of the less immediately apparent reasons why caesarean delivery has been normalized and rendered invisible in the landscape of modern childbirth. I 
offer evidence for considering the action of caesarean delivery within the set of practices that form what we might consider to be the conventions of normative femininity.

\section{Materials}

I begin with what likely encompasses the materials of caesarean delivery, and assert that beyond the knives, scalpels, anesthesia, and the operating room, the materiality of caesarean delivery is constituted by the physicality of the hospital itself. Existing research has established that the relocation of birth from the home to the hospital was accompanied by the perception that childbirth was an illness necessitating medical management (Jolly, 2010). This move legitimized women adopting a sick role (Myers, Grasmick, Dinitto, Key, \& Corse, 1990), including a desire to fulfill an obligation to cooperate in the process of getting well (Segall, 1976). That cooperation is material in nature, indeed it resides in the very way a woman experiences the physicality of her body. As a hospital patient, a woman concedes her bodily autonomy and expertise, and is encouraged to experience her body in a more atomized fashion; as an object or a set of objects, over which she may have little understanding and authority (E. Martin, 2001). This feature of the hospital/patient relationship is captured nicely in this excerpt taken from a woman interviewed after her caesarean delivery,

"They said I had preeclampsia, but I never had any of the symptoms. No blurry vision. No headaches. None of that. I was fine ... My doctor was like, "you may be fine, but your body isn't." What does that even mean? How is my body sick, and I'm not feeling any of it? I didn't get that, and it didn't matter that I didn't get that" (Burcher, Cheyney, Li, Hushmendy, \& Kiley, 2016, p. 4).

The materiality of the caesarean aligns with a hospital infrastructure that encourages women to subsume their bodily experiences in favor of external and seemingly objective bodily evaluation. For the birthing woman, her body (or body parts) is separated out from her person, reduced to the status of mere instruments, or regarded as if those parts were capable of representing her (Bartky, 1988).

Sociologists of gender have joined feminist philosophers in contending that being treated merely as a body parallels the material reality of women's daily life and the social practices that 
constitute womanhood. Material feminist literature on the body has long established that a central feature of a woman's life is her dampening of her own expertise over her bodily experiences and instead prioritizing an outside appraisal of her embodiment (Bartky, 1988; Beauvoir, 1952; Young, 2005). The development and ongoing elaboration of objectification theory (Moradi \& Huang, 2008) reveals the degree to which women's practices are shaped by "an array of experiences that appear to be uniquely female" (Fredrickson \& Roberts, 1997, p. 196). Iris Marion Young was among the many scholars interested in the materialism of women's embodiment, and explored how women experience their bodies as fragile encumbrances rather than as the medium for enacting their aims. She writes, "[Women] have more of a tendency than men to greatly underestimate our bodily capacity. We decide beforehand - usually mistakenly - that the task is beyond us and thus give it less than our full effort. At such a halfhearted level, of course, we cannot perform the tasks, become frustrated, and fulfill our own prophecy." (Young, 2005, p. 34). Others have elaborated on this to argue that such orientation impacts a woman's ability to enter into a "peak motivational state" or a state of "flow" (Csikszentmihalyi, 2014; Szymanski \& Henning, 2007), and inhibits one's capacity for marshaling mental and physical resources to meet life's challenges (Reiger \& Dempsey, 2006). Still others have discussed how conventionally feminine practices such as women's restrictive eating and their learned ability to avoid hunger cues manifests physically over time to inhibit bodily awareness (hunger, heartbeat, sexual arousal, breath, etc.) leading to a more distant connection to their physical bodies (Tiggemann \& Kuring, 2004). And while no one asserts that these particular actions and practices are experienced by all women at all times, nor even to the same degree, they nonetheless maintain that many of the actions and practices associated with being a woman share among them a general lack of body confidence, bodily connection, and bodily authority. That this is in perfect sympathy with the materiality of the hospital, and the pursuit of obstetrics more generally, has consequences for the decision to deliver via caesarean. The hospital, and all of the practices that it represents, suggests that women may find familiarity in the specific decision regarding caesarean, given that it likely aligns with other actions and practices that serve as central features of women's lives.

\section{Competences}

Shove et al. maintain that if we are to take social practice as our analytical unit, we need to also 
consider the ways that specific practices necessitate particular competences, and generate certain sets of skills. What competences are associated with the decision to pursue (or consent to) a caesarean delivery? I have already suggested that the practice of being a hospital patient aligns seamlessly with the practices of bodily disconnection so intrinsic to a woman's experience of her body. Indeed much of what women know about their bodies is mediated by medicine, particularly with regards to reproductive moments such as menstruation, childbirth, and menopause. Nearly one in five young women now use hormone-based oral contraceptive pills or implants to suppress their menstrual periods to four per year (using products such as Seasonale or Seasonique) or to avoid menstruation all together (using products such as Lybrel, the NuvaRing, or the Nexplanon implant), and an even higher number express a desire to do so in the future (Lakehomer, Kaplan, Wozniak, \& Minson, 2013). Rates of hormone replacement therapy (now called hormone therapy) to treat menopausal symptoms were similarly high before the Women's Health Initiative (WHI) released data in 2002 demonstrating that long-term use of estrogen and progestin raised the risk of heart disease, stroke, and invasive breast cancer (Niland \& Lyons, 2011). And while the safety of these practices is beyond the scope of this discussion, there has been widespread concern that their normalization is "harmful for women's interpretations of their bodily experiences" (Schatzki, 1996, p. 1244). Biomedical discourses construct the female body and its reproductive functions in negative ways by invoking notions of failure, and by suggesting the female body is inherently diseased or that it is merely a mechanistic set of parts (E. Martin, 2001). A caesarean delivery aligns with other practices increasingly familiar to women: those that offer medical management of and involvement in certain aspects of her reproductive body. As a result, caesarean delivery dovetails with a set of skills that rely on medical technologies to mediate women's reproductive experiences.

I posit that caesarean delivery is similarly imbricated within a set of body practices that form a general lack of body confidence for women. Certainly the national attention now paid to the young age at which girls' begin experiencing and struggling against bulimia and anorexia nervosa is testament to the pervasiveness of this phenomenon, and the disordered eating practices they generate. Research has shown that, until puberty, girls are the hardier sex, with higher rates of physical and mental health, and more competence in social relations (Brumberg, 1997). Once puberty arrives, however, that advantage evaporates and the likelihood that a girl 
experiences body-related clinical depression increases drastically (Rodgers, Paxton, \& Chabrol, 2010). "By age thirteen, 53 percent of American girls are unhappy with their bodies; by age seventeen, 78\% are dissatisfied" (Brumberg, 1997, p. xxiv). In Australia, girls continue to identify body image as one of their top three personal concerns (Baily et al., 2016). Bodily practices that construct the body as a nemesis take on new import at adolescence and continue apace thorough out a woman's life. Most obviously, practices such as dieting and, increasingly, cosmetic surgery (Henderson-King \& Henderson-King, 2005) serve as indicators of widespread body discord, and their prevalence normalizes women's bodily antagonism. Similarly, practices such as smoking and even substance abuse have been found to connect with a woman's bodily anxiety and her more general experience of body conflict (Fiissel \& Lafreniere, 2006; Moradi \& Huang, 2008). I argue here that these particular practices align over time to constitute what I propose be an adversarial body relationship that is pervasive and ongoing. I find this concept to be analytically useful: women become fluent in the practice of body discord through myriad socializing forces and thus female embodiment becomes largely characterized by bodily antagonism. Furthermore, I suggest that antagonistic female embodiment is a valuable theoretical frame we may use to capture this diverse set of practices that increasingly characterize what it means to be a woman in western society and to have an adversarial relationship to one's body. The practice of antagonistic female embodiment is conceptually rich within the context of the caesarean debate as it offers insight into how caesarean delivery may parallel a set of bodily competencies with which women are already quite conversant. A woman's body has long been her adversary, a foe. A delivery method that offers women an opportunity to circumvent her reproductive body mirrors other practices that meet body anxiety with medicalization and exacerbate the pervasive body discord that women experience. That these issues are central features of our social world suggest that women are fluent in skills required to navigate this adversarial body relationship, and caesarean delivery may be emblematic of antagonistic female embodiment.

\section{Meanings}

The third element of analyzing social practices requires a consideration of social meanings. In particular, this entails focusing attention on how social practices become embodied and how they become socially significant. In their discussion of practice theory, Shove, Pantzar, and 
Watson admit that putting a finger on meanings is "tricky territory", but suggest that we begin with "the social and symbolic significance of participation at any one moment" (2012, p. 23). The social and symbolic significance of caesarean delivery is brought into stark relief by an analysis of a woman's everyday life wherein her body confidence and bodily capacity is routinely undermined, where her reproductive body is medically managed, and where the very materiality of the hospital requires her to relinquish bodily authority. In short, a caesarean delivery harmonizes with many of the practices that constitute normative femininity today. Passivity, weakness, docility, body anxiety, and a lack of self-assuredness serve as foundational practices from which we continue to construct normative femininity, and this may have very real consequences for how women approach delivery. Do women recognize something in caesarean delivery that seamlessly aligns with other practices that inform normative gender expectations? Is there an element of convention in an act that facilitates women's ability to bypass the messy, intense, ugly, possibly painful and decidedly physically exertive experience of labor and vaginal delivery (Jolly, 2015)? Does a caesarean in some way enact what we value in womanhood today? It well and truly might, and - by considering caesarean within the context of social practice - we may bring to light some of the embodied understandings that make women amenable (or at least less resistant) to consenting to surgical delivery. Because though childbirth is still widely considered to be pre-social, biological, natural, medical, or somehow beyond the reach of culture, it is not; it is always socially interpellated. Decisions about birth are “socially embedded” (Behruzi, Hatem, Goulet, Fraser, \& Misago, 2013, p. 206) and childbirth “is everywhere socially marked and shaped” (Jordan, 1993, p. 3).

Shove et al. remind us that when considering social practices, our focus should remain on the interdependence of materials, competences, and meanings (2012, p. 24) and I offer that this interdependency reflects women's substantial fluency with these practices wherever they may manifest. Indeed, the social practices of femininity are performed "against the background of a pervasive sense of bodily deficiency," accounting for "their compulsive or even ritualistic character" (Bartky, 1988, p. 139). The practices of femininity are familiar, normalized, and rendered invisible because of their routine pervasiveness, even - as I suggest here - during a woman's decision about whether, and/or when, she will consent to a caesarean delivery. Gender socialization is an uneven transfer of social to individual, and is certainly not a fait accompli; 
nonetheless, gender norms are remarkably durable. If we follow Reckwitz one step further, we would join him in concluding that - like other social practices - the decision to consent to caesarean is a "routinized bodily activity" or a "movement of the body" that results from the “interconnected complexes of behavior acts" (Reckwitz, 2002, p. 253) that constitute normative femininity.

The action of caesarean delivery within a social practice analysis goes even further, in that it illuminates possible connections that may exist between seemingly unrelated phenomena. Take for instance the rise of tokophobia (a birthing woman's clinical fear of vaginal childbirth so severe that it necessitates a caesarean delivery), a diagnosis rising in prominence (Hofberg $\&$ Brookington, 2000; Saisto \& Halmesmäki, 2003). Tokophobia has been conceived of as a psychological disorder, an individual emotional response that occasionally surfaces in pregnant women. In short, it is seen as an anomaly. Given the above established constitutive practices that form the tenets of normative femininity, might it also be possible that tokophobia (and the body discord and medical reliance it indexes) is not merely an individual psychological response to vaginal birth, but is itself yet another constitutive part of a similar social practice? Is a woman's tokophobic response to vaginal delivery a form of social practice, merely another handmaiden of normative femininity? Have women "learned to be bodies in a certain way" (Reckwitz, 2002, p. 251)? Can we recognize a familiar embodiment here, a harmony between the growing appeal of caesarean delivery, a dismissal of the role of vaginal labor, and the rising occurrence of women's debilitating fear of vaginal childbirth (Wang, 2017)? Future research is needed to consider how practices hold each other together across various socio-historical moments. I posit here that tokophobia, like cesarean delivery, is not a mere psychological particularism, but is instead a practice. Both are consequences of a society that subtly undermines a woman's body confidence and medicalizes her body as part and parcel of the practice of normative femininity.

\section{Beyond birth: Considering the sociological implications}

Discussing caesarean within the framework of social practice provides insight into how this specific phenomenon is tethered to other practices associated with normative femininity, and explains why caesarean delivery may now have such widespread appeal. So while a practice 
analysis of caesarean delivery may not immediately resemble many of the more conventional social practices put under the microscope, it is nonetheless recognizable as "a 'type' of behaving and understanding that appears at different locales and at different points of time and is carried out by different body/minds" (Reckwitz, 2002, p. 252). I have argued here that new ways of understanding the growing appeal of caesarean delivery are available when using a social practice framework and, more generally, have endeavored to bring sociological theories to bear on a matter of public health (Pound \& Campbell, 2015). Specifically, I have suggested that in considering the constitutive elements that serve to normalize and render invisible the social practices of normative femininity, we can begin to understand why women might be amenable to (or at least less resistant to) caesarean delivery despite the health risks it poses to mothers and babies. It is apt that caesarean delivery aligns so well with the materiality of the hospital, the medicalization of women's bodies, and women's adversarial body relationship. This is not to suggest that women are merely caged by the social conventions of the day, but to more fully consider how this particular action may align with others to constitute social practices that remain largely invisible because of their prevalence.

Recognizing caesarean as a constitutive element of a social practice may assist women's health practitioners in addressing the rising rate of caesarean delivery by moving the discussion away from one of individual responsibility or of social and economic determinism, and may instead refocus the conversation on how we might intervene into the very social practices that organize women's lives. Social practice theory offers another way to analyze what has come to be an intractable public health issue, and goes beyond blaming women for their health choices. Instead, the choice to have a caesarean (or to concede to that method of delivery) is influenced by the practices women enact and cannot be understood as separate from the various social practices that constitute normative femininity. We are, after all "body/minds who 'carry' and 'carry out' social practices" (Reckwitz, 2002, p. 258) and it is these practices that should occupy our attention. The debate about caesarean delivery deserves more than the factious treatment that it has heretofore been afforded in the public sphere if we are to consider strategies to address this as a public health issue. Sociologists of health are well positioned to offer insight into that discussion.

Moving away from conceiving of caesarean as either an isolated individual decision or one 
largely determined by broader social forces offers possibilities for intervention and change. In this way, we might imagine decoupling this practice from other social practices of normative femininity. Specifically we might encourage practices that use the moment of pregnancy to more squarely address women's ongoing body discord and challenge the routine medicalization of women's bodies. Activism in this direction has the added potential to radiate outwards into other aspects of women's lives and to curtail women's recruitment into social practices associated with normative femininity that are unhealthy and dangerous. That activism around birth may inform a new body politic, one based on bodily competency rather than body distrust/disgust suggests real emancipatory potential; not that this merely has the potential to address restrictive gender norms, but indeed has that as its very goal (Jolly, 2017). What might be possible if the practices of femininity were marked by a sense of bodily capacity, of prevailing over adversity, of being physically dexterous and intrepid?

Addressing women's adversarial embodiment through a focus on childbirth and delivery practices may provide a new platform for social activism, and one that aligns with the growing recognition that childbirth and motherhood may well be the unfinished business of feminism. Scholars (O'Reilly, 2016; Rich, 1976; Ruddick, 1995) have long observed a disconnect between the minimal representation of birth and motherhood in contemporary scholarship and the more central role that these moments play in the actual lives of most women. Given that more than 4 out of 5 women give birth in their lifetime (Livingston \& Cohn, 2010), much work remains to be done. The extant work in health sociology happening at the intersection of gender, embodiment, and medicalization, should continue to center issues of pregnancy, childbirth, and motherhood in these discussions. Childbirth may also serve as a much needed fulcrum between feminist theory and medical sociology (Annandale \& Clark, 1996), promising deeper reserves that have remained largely unprospected.

I offer here that childbirth practices are but one of the many vantage points from which to investigate the overlap between practice theory, normative gender, and the body, and would encourage others to consider this as a valiant and valuable trajectory of sociological scholarship on health. In particular, analyses that employ a social practice framework offer a novel heuristic device to address the intractable nature of the many social problems facing women, particularly because at its very nature it grasps that "routinized bodily performances are the site of the social 
and - so to speak - of "social order"' (Reckwitz, 2002, p. 253). Those interested to understand why childbirth has taken a surgical turn may benefit from a more sustained encounter with the innovative work on practice theory being done in the field of sociology. From there we can more deeply consider how "birthgiving [...] is never unmediated by cultural meanings and practices: at both collective and individual level birth is thus 'done"' (Reiger \& Dempsey, 2006, p. 369) as part of women's embodied practice. 
Almeling, R. (2015). Reproduction. Annual Review of Sociology, 41(1), 423-442. doi:doi:10.1146/annurev-soc-073014-112258

Annandale, E., \& Clark, J. (1996). What is gender? Feminist theory and the sociology of human reproduction. Sociology of Health \& IIIness, 18(1), 17-44. doi:10.1111/1467-9566.ep10934409

Baily, V., Baker, A.-M., Cave, L., Fildes, J., Perrens, B., Plummer, J., \& Wearring, A. (2016). Mission Australia's 2016 National Youth Survey Report. Retrieved from https://www.missionaustralia.com.au/what-we-do/research-evaluation/youth-survey: https://www.missionaustralia.com.au/what-we-do/research-evaluation/youth-survey

Bartky, S. (1988). Foucault, Femininity, and the Modernization of Patriarchal Power. In I. Diamond \& L. Quinby (Eds.), Feminism and Foucault: Reflections on Resistance. Chicago: Northeastern University Press.

Basso, O., \& Baird, D. D. (2003). Infertility and preterm delivery, birthweight, and Caesarean section: a study within the Danish National Birth Cohort. Human Reproduction, 18(11), 2478-2484. doi:10.1093/humrep/deg444

Beauvoir, S. d. (1952). The Second Sex: Vintage Books (Random House).

Beckett, K. (2005). Choosing Cesarean. Feminist Theory, 6(3), 251-275. doi:10.1177/1464700105057363

Behruzi, R., Hatem, M., Goulet, L., Fraser, W., \& Misago, C. (2013). Understanding childbirth practices as an organizational cultural phenomenon: a conceptual framework. BMC Pregnancy and Childbirth, 13(205), 1-10. doi:10.1186/1471-2393-13-205

Bergeron, V. (2007). THE ETHICS OF CESAREAN SECTION ON MATERNAL REQUEST: A FEMINIST CRITIQUE OF THE AMERICAN COLLEGE OF OBSTETRICIANS AND GYNECOLOGISTS' POSITION ON PATIENTCHOICE SURGERY. Bioethics, 21(9), 478-487. doi:10.1111/j.1467-8519.2007.00593.x

Bobel, C. (2010). New Blood: Third Wave Feminism and the Politics of Menstruation. New Brunswick, NJ, USA: Rutgers University Press.

Bourdieu, P. (1984). Distinction: A Social Critique of the Judgement of Taste (R. Nice, Trans.). Cambridge, Massachusetts: Harvard University Press.

Brubaker, S. J. (2007). Denied, Embracing, and Resisting Medicalization: African American Teen Mothers' Perceptions of Formal Pregnancy and Childbirth Care. Gender and Society, 21(4), 528-552. doi:10.1177/0891243207304972

Brumberg, J. J. (1997). The Body Project: An Intimate History of American Girls. New York: Random House, Inc.

Burcher, P., Cheyney, M. J., Li, K. N., Hushmendy, S., \& Kiley, K. C. (2016). Cesarean Birth Regret and Dissatisfaction: A Qualitative Approach. Birth, n/a-n/a. doi:10.1111/birt.12240

Chen, C.-S., Liu, T.-C., Chen, B., \& Lin, C.-L. (2014). The failure of financial incentive? The seemingly inexorable rise of cesarean section. Social Science \& Medicine, 101, 47-51. doi:http://dx.doi.org/10.1016/i.socscimed.2013.11.010

Creighton, G., \& Oliffe, J. L. (2010). Theorising masculinities and men's health: A brief history with a view to practice. Health Sociology Review, 19(4), 409-418. doi:10.5172/hesr.2010.19.4.409

Csikszentmihalyi, M. (2014). Applications of flow in human development and education : the collected works of Mihaly Csikszentmihalyi. New York: Springer.

Declercq, E., Barger, M., Cabral, H. J., Evans, S. R., Kotelchuck, M., Simon, C., . . Heffner, L. J. (2007). Maternal outcomes associated with planned primary cesarean births compared with planned vaginal births. Obstet Gynecol, 109(3), 669-677. doi:10.1097/01.aog.0000255668.20639.40

Dietz, H. P., \& Campbell, S. (2016). Toward normal birth--but at what cost? American Journal of Obstetrics and Gynecology, 215(4), 5. doi: http://dx.doi.org/10.1097/01.aoa.0000521212.65911.d3

Doherty, E., \& Eichenwald, E. (2004). Cesarean delivery: Emphasis on the neonate. Clin Obstet Gynecol, 47, 9. doi:10.1097/00003081-200406000-00007 
Ecker, J. (2013). ELective cesarean delivery on maternal request. JAMA, 309(18), 1930-1936. doi:10.1001/jama.2013.3982

Fausto-Sterling, A. (2000). Sexing the body: Gender politics and the construction of sexuality. New York: Basic Books.

Fiissel, D. L., \& Lafreniere, K. D. (2006). Weight control motives for cigarette smoking: Further consequences of the sexual objectification of women. Feminism \& Psychology, 16, 327-344. doi:10.1177/0959353506067850

Foucault, M. (1977). The History of Sexuality (R. Hurley, Trans. Vol. 1: An Introduction). New York: Vintage.

Fredrickson, B. L., \& Roberts, T.-A. (1997). Objectification theory: Towards Understanding Women's Lived Experiences and Mental Health Risks. Psychology of Women Quarterly, 21(2), 173. doi:10.1111/j.1471-6402.1997.tb00108.x

Freidenfelds, L. (2009). The modern period: menstruation in twentieth-century America. Baltimore: Johns Hopkins University Press.

Giddens, A. (1979). Central Problems in Social Theory: Action, Structure, and Contradiction in Social Analysis. Berkeley, CA: University of California Press.

Grosz, E. (1994). Volatile Bodies: Indiana University Press.

Henderson-King, D., \& Henderson-King, E. (2005). Acceptance of cosmetic surgery: Scale development and validation. Body Image, 2(2), 137-149. doi:10.1016/j.bodyim.2005.03.003

Hofberg, K., \& Brookington, I. F. (2000). Tokophobia: an unreasoning dread of childbirth: A series of 26 cases. The British Journal of Psychiatry, 176(1), 83-85. doi:10.1192/bjp.176.1.83

Jolly, N. (2010). Childbirth. In A. O'Reilly (Ed.), The Encyclopedia of Motherhood (Vol. 1, pp. 183-189): Sage.

Jolly, N. (2015). Does labor mean work? Queries into the role of femininity in childbirth. In N. Burton (Ed.), Natal Signs: Cultural Representations of Pregnancy, Birth and Parenting (pp. 218-231). Toronto: Demeter Press.

Jolly, N. (2017). Sexy Birth: Breaking Hollywood's Last Taboo. Sexualities, 20(8). doi:10.1177/1363460717699770

Jordan, B. (1993). Birth in Four Cultures (4 ed.). Prospect Heights, Ill.: Waveland Press.

Klein, M. C. (2012). Cesarean Section on Maternal Request: A Societal and Professional Failure and Symptom of a Much Larger Problem. Birth, 39(4), 305-310. doi:10.1111/birt.12006

Lakehomer, H., Kaplan, P. F., Wozniak, D. G., \& Minson, C. T. (2013). Characteristics of scheduled bleeding manipulation with combined hormonal contraception in university students. Contraception, 88(3), 426-430. doi:http://dx.doi.org/10.1016/i.contraception.2012.12.012

Livingston, G., \& Cohn, D. V. (2010). Childlessness Up Among All Women' Down Among Women with Advanced Degrees. Pew Research Center Social \& Demographic Trends. Retrieved from http://www.pewsocialtrends.org/2010/06/25/childlessness-up-among-all-women-downamong-women-with-advanced-degrees/ website:

Lock, M. (1993). Encounters with aging: Mythologies of menopause in Japan and North America. Berkeley: University of California Press.

Lupton, D., \& Schmied, V. (2013). Splitting bodies/selves: women's concepts of embodiment at the moment of birth. Sociology of Health \& IIIness, 35(6), 828-841. doi:10.1111/j.14679566.2012.01532.x

Macdonald, M. (2006). Gender expectations: natural bodies and natural births in the new midwifery in Canada. Med Anthropol Q, 20(2), 235 - 256. doi:10.1525/maq.2006.20.2.235

Malacrida, C., \& Boulton, T. (2012). Women's Perceptions of Childbirth "Choices": Competing Discourses of Motherhood, Sexuality, and Selflessness. Gender \& Society, 26(5), 748-772. doi:10.1177/0891243212452630 
Maller, C. J. (2015). Understanding health through social practices: performance and materiality in everyday life. Sociology of Health \& IIIness, 37(1), 52-66. doi:10.1111/1467-9566.12178

Martin, E. (2001). The Woman in the Body: A Cultural Analysis of Reproduction. New York: Beacon Press.

Martin, K. (2003). Giving Birth Like A Girl. Gender \& Society, 17(1), 54-72. doi:10.1177/0891243202238978

Michaluk, C. A. (2012). Having an Elective Cesarean: Doing What's Best for Me. Journal of Obstetric, Gynecologic, \& Neonatal Nursing, 41(s1), S126-S127. doi:10.1111/j.1552-6909.2012.01362_12.x

Miesnik, S. R., \& Reale, B. J. (2007). A Review of Issues Surrounding Medically Elective Cesarean Delivery. Journal of Obstetric, Gynecologic, \& Neonatal Nursing, 36(6), 605-615. doi:10.1111/j.15526909.2007.00196.x

Moradi, B., \& Huang, Y.-P. (2008). OBJECTIFICATION THEORY AND PSYCHOLOGY OF WOMEN: A DECADE OF ADVANCES AND FUTURE DIRECTIONS. Psychology of Women Quarterly, 32(4), 377-398. doi:10.1111/j.1471-6402.2008.00452.x

Morris, T. (2013). Cut it out : the C-section epidemic in America. New York: New York University Press.

Murthy, K., Grobman, W., Lee, T., \& Holl, J. (2007). Association between rising professional liability insurance premiums and primary cesarean delivery rates. Obstet Gynecol, 110(6), 1264-1269. doi:10.1097/01.AOG.0000287294.89148.23

Myers, S., Grasmick, H., Dinitto, D., Key, W., \& Corse, S. (1990). The Social Rights and Responsibilities of Pregnant Women: An Application of Parsons's Sick Role Model. Journal of Applied Behavioral Science, 26(2), 157-173. doi:10.1177/0021886390262005

Niland, P., \& Lyons, A. C. (2011). Uncertainty in medicine: Meanings of menopause and hormone replacement therapy in medical textbooks. Social Science \& Medicine, 73(8), 1238-1245. doi:http://dx.doi.org/10.1016/i.socscimed.2011.07.024

O'Reilly, A. (2016). Matricentric Feminism. Toronto, Canada: Demeter Press.

Ortner, S. (1984). Theory in Anthropology since the Sixties. Comparative Studies in Society and History, 26(1), 126-166. doi:10.1017/S0010417500010811

Plante, L. (2006). Public Health Implications of Cesarean on Demand. Obstetrical \& Gynecological Survey, 61(12), 807-815. doi: 10.1097/01.ogx.0000248826.44123.73

Pound, P., \& Campbell, R. (2015). Locating and applying sociological theories of risk-taking to develop public health interventions for adolescents. Health Sociology Review, 24(1), 64-80. doi:10.1080/14461242.2015.1008537

Reckwitz, A. (2002). Toward a Theory of Social Practices: A Development in Culturalist Theorizing. European Journal of Social Theory, 5(2), 243-263. doi:10.1177/13684310222225432

Reiger, K., \& Dempsey, R. (2006). Performing birth in a culture of fear: an embodied crisis of late modernity. Health Sociology Review, 15(4), 364-373. doi:10.5172/hesr.2006.15.4.364

Rich, A. (1976). Of Woman Born: Motherhood as Experience and Institution. New York and London: W.W. Norton.

Rodgers, R. F., Paxton, S. J., \& Chabrol, H. (2010). Depression as a Moderator of Sociocultural Influences on Eating Disorder Symptoms in Adolescent Females and Males. Journal of Youth and Adolescence, 39(4), 393-402. doi:10.1007/s10964-009-9431-y

Ruddick, S. (1995). Maternal Thinking: Towards a Politics of Peace. Boston, MA: Beacon Press.

Saisto, T., \& Halmesmäki, E. (2003). Fear of childbirth: a neglected dilemma. Acta Obstetricia et Gynecologica Scandinavica, 82(3), 201-208. doi:10.1034/j.1600-0412.2003.00114.x

Schatzki, T. (1996). Social practices: A wittgensteinian approach to human activity and the social. Cambridge: Cambridge University Press.

Segall, A. (1976). The sick role concept: understanding illness behavior. j. Health Soc. Behav., 17, 163170. 
Sevelsted, A., J. Stokholm, K. Bonnelykke, H. Bisgaard. (2015). Cesarean Section and Chronic Immune Disorders. Pediatrics, 135(1), 6. doi:10.1542/peds.2014-0596

Shove, E., Pantzar, M., \& Watson, M. (2012). The Dynamics of Social Practice: Everyday Life and how it Changes. London: Sage Publications.

Song, S. (2004). Too Posh to Push? Time Magazine. 11 Apr.

Statistics, A. B. o. (2006). Population Projections, Australia. Retrieved from Canberra: http://www.abs.gov.au/ausstats/abs@.nsf/mf/3222.0

Szymanski, D. M., \& Henning, S. L. (2007). The role of self-objectification in women's depression: A test of objectification theory. Sex Roles, 56, 45-53. doi:10.1007/s11199-006-9147-3

Tiggemann, M., \& Kuring, J. K. (2004). The role of body objectification in disordered eating and depressed mood. British Journal of Clinical Psychology, 43(3), 299-311. doi:10.1348/0144665031752925

Wang, E. (2017). Requests for cesarean deliveries: The politics of labor pain and pain relief in Shanghai, China. Social Science \& Medicine, 173, 1-8. doi:http://dx.doi.org/10.1016/j.socscimed.2016.11.032

Welfare, A. I. o. H. a. (2015). Australia's mothers and babies 2013 - in brief. Retrieved from Canberra ACT: http://www.aihw.gov.au/WorkArea/DownloadAsset.aspx?id=60129554140

WHO. (1985). Appropriate technology for birth. Lancet, 2(8452), 2. doi: http://dx.doi.org/10.1016/S0140-6736(85)92750-3

WHO. (2015). Caesarean sections should only be performed when medically necessary. Retrieved from http://www.who.int/mediacentre/news/releases/2015/caesarean-sections/en/

Young, I. M. (2005). On female body experience: "Throwing Like a Girl" and Other Essays. Oxford: Oxford University Press.

Zwecker, P., Azoulay, L., \& Abenhaim, H. A. (2011). Effect of fear of litigation on obstetric care: a nationwide analysis on obstetric practice. Am J Perinatol, 28(4), 277-284. doi:10.1055/s-00301271213 